\title{
Emergency Tracheostomy for Acute Hematoma of the Floor of the Oral Cavity in Patient Under Anticoagulant Therapy: Case Report and Systematic Review
}

\author{
H Ardhaoui, S Halily*, S Rouadi, R Abada, M Roubal and M Mahtar
}

Department of Oto-Rhino-Laryngology, Head and Neck Surgery, Casablanca university hospital, Morocco

Submission: December 09, 2019; Published: December 16, 2019

*Corresponding author: S Halily, Department of Oto-Rhino-Laryngology, Head and Neck Surgery, Casablanca university hospital, Casablanca, Morocco

\begin{abstract}
Spontaneous hematoma of the floor of the mouth induced by anti-vitamin $\mathrm{K}$ is extremely rare but considered as a potentially fatal complication especially if it is located at the floor of the mouth. Acenocoumarol is a commonly used as an oral anticoagulant agent. It is used in treating thromboembolic disease. Spontaneous bleeding without a history of trauma is a possible complication. The most common sites of bleeding are the genitourinary and gastrointestinal tracts, the central nervous system, the nose (epistaxis). We report a case of an acute hematoma of the floor of the oral cavity developed during oral anticoagulation therapy requiring an emergency tracheostomy. The objective of this study is to describe, from our clinical case and the literature review, the clinical and radiological features of the spontaneous bleeding into the floor of the oral cavity and to discuss its therapeutic management.
\end{abstract}

Keywords: Hematoma; Floor of the Mouth; Anticoagulation; Tracheostomy

\section{Introduction}

The production of hemorrhage in the floor of the mouth it is usually associated with trauma especially the mandibular fractures or with some surgical procedures as the dental implant placement [1] and in relation to the use of acenocoumarol, streptokinase or heparin, wafarine. Hemorrhagic complications associated with the use of anticoagulant therapy have been well documented [2].

Case Report

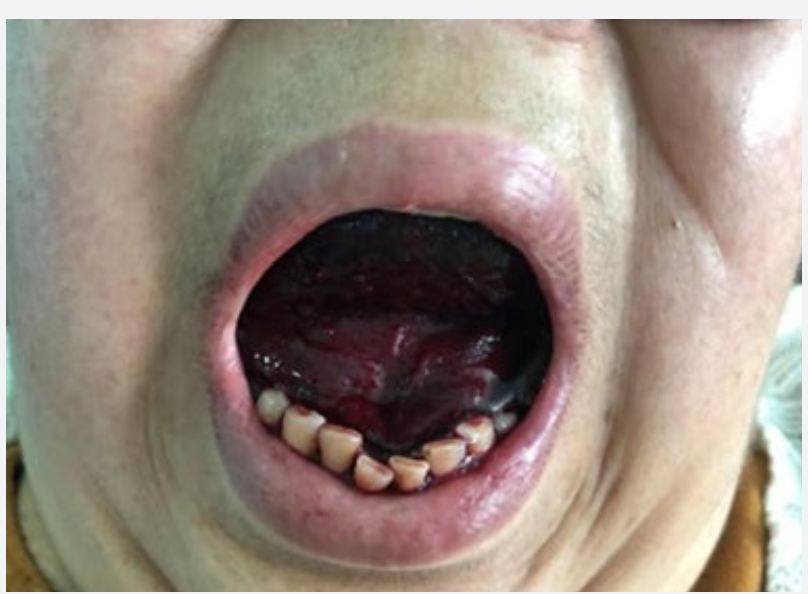

Figure 1: Hematoma of the floor of mouth with superior and posterior displacement of the tongue causing obstruction of the upper airway. 


\section{Global Journal of Otolaryngology}

A 70-year-old woman presented to the emergency department with respiratory distress caused by an extensive spontaneous bleeding into the floor of the oral cavity (Figure 1). The patient was on anticoagulant therapy with acenocoumarol for atrial fibrillation. Given the impossibility to perform an intubation, an emergency tracheostomy was performed under local anesthesia.

Computed tomography (CT) scan showed an uncollected and poorly limited hematoma of the floor of the mouth fusing between the supra hyoid muscles (Figure 2). The rate of prothrombin was $31 \%$ and the International Normalized Ratio (INR) was 4. The anticoagulant therapy was stopped then the patient received injections of vitamin $\mathrm{K}$ associated with infusion of fresh frozen plasma in the intensive care unit. After normalization of the hemostasis blood tests, the acenocoumarol was reintroduced progressively without complications. The patient was successfully extubated after one week (Figure 3).

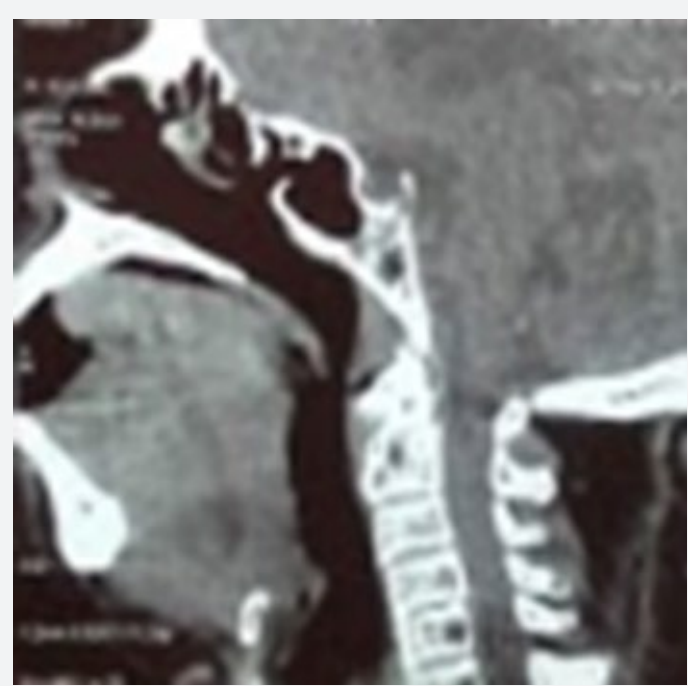

Figure 2: Hematoma of the floor of mouth with superior and posterior displacement of the tongue causing obstruction of the upper airway.

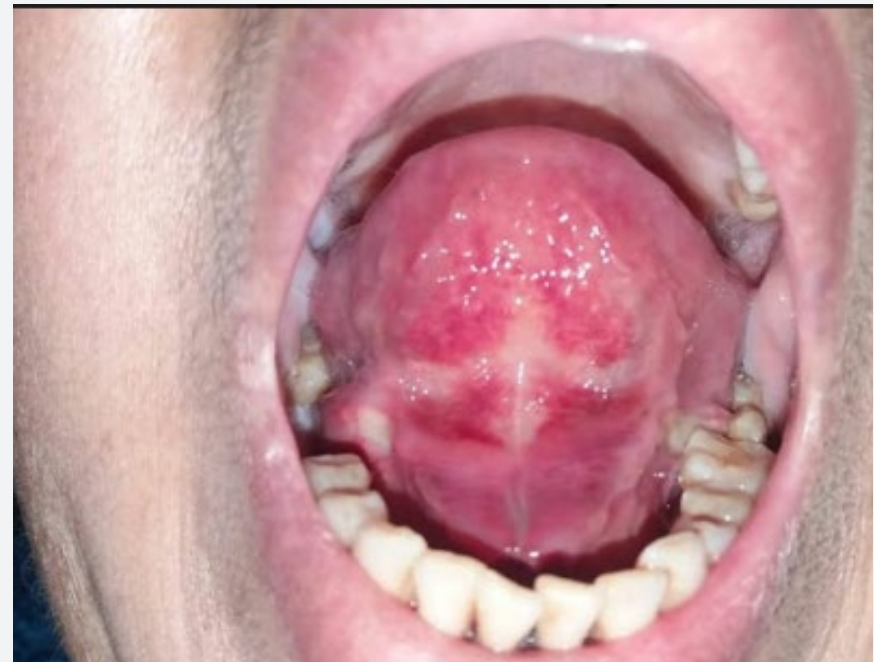

Figure 3: Regression of the hematoma after one week.

\section{Discussion}

Oral anticoagulants are very commonly prescribed. Their function is to depress activity of coagulation factors like thrombin, prothrombin, and factors VII, IX, and X [3,4]. Several pathologies require an adequate anticoagulation. Hemorrhage secondary to anticoagulant therapy is rare. The most common the locations for bleeding are genitourinary, gastrointestinal, cutaneous, and intracranial [5]. Hematoma of the floor of the mouth is rare even though retropharyngeal, laryngeal bleeding have been caused by anticoagulant [6]. 
We report in this article a case illustrates a very uncommon and life-threatening complication of the acenocoumarol therapy.

The cause of respiratory distress is due to the tongue moved backward and upward like Ludwig's angina [3]. The signs associated to this hematoma are the following: cervical mass, sublingual swelling, ecchymosis or retropharyngeal bulge, tachypnea, and stridor [7]. According to the review of Garcia D, hematoma due to acenocoumarol is rarer than wafarine because of nine cases of hematoma of the floor of the mouth only two were due to the use of acenocoumarol [8,9]. The spontaneous disappearance of the hematoma is the natural course of bleeding. It only occurred if oral anticoagulation was stopped and FFP and/ or vitamin $\mathrm{K}$ were administered [2,7-9]. As it has been previously observed in our case, the use of subcutaneous heparin or antiplatelet drugs would be desirable if patient needed an ulterior coagulation treatment [2].

In most cases reported in the literature a tracheotomy was temporarily necessary [10] because the strict control of the airway is assured by endotracheal intubation, tracheostomy, or cricothyrotomy [11]. Surgical drainage of the sublingual hematoma was not indicated because it could increase the bleeding as well as the swelling with the result of complete aggravating airway obstruction. However, other authors require this drainage in order to evacuate any collection of blood [8].

\section{Conclusion}

Hematoma of the floor of the mouth is a rare but potentially serious complication of acenocoumarol therapy. Reversal of anticoagulation with low threshold for artificial airway placement in the event of airway compromise is the treatment of choice.

\section{References}

1. Goodacre CJ, Bernal G, Rungcharassaeng K, Kan JY (2003) Clinical complications with implants and implant prostheses. J Prosthet Dent 90: $121-132$

2. Cohen AF, Warman SP (1989) Upper airway obstruction secondary to warfarin-induced sublingual hematoma. Arch Otolaryngol Head Neck Surg 115: 718-720.

3. Lepore ML (1976) Upper airway obstruction induced by warfarin sodium. Arch Otolaryngol 102: 505-506.

4. Rosenbaum L, Thurman P, Krantz SB (1979) Upper airway obstruction as a complication of oral anticoagulation therapy. Report of three cases. Arch Intern Med 139: 1151-1153.

5. Lee NJ, Peckitt NS (1996) Treatment of a sublingual haematoma with medicinal leeches: report of a case. J Oral Maxillofac Surg 54: 101-103.

6. Uong TC, Burtch G, Shatney CH (1986) Upper airway obstruction as a complication of oral anticoagulation therapy. Crit Care Med 14: 830831.

7. Boster SR, Bergin JJ (1983) Upper airway obstruction complicating warfarin therapy-with a note on reversal of warfarin toxicity. Ann Emerg Med 12: 711-715.

8. Gooder P, Henry R (1980) Impending asphyxia induced by anticoagulant therapy. J Laryngol Otol 94: 347-352.

9. Bachmann P, Gaussorgues P, Piguat J, Gueugniaud PY, Piperno D, et al (1987) Pulmonary edema secondary to warfarin-induced sublingual and laryngeal haematoma. Crit Care Med 15: 1074-1075.

10. M Mouhaoui, K Khaleq, K Yaqini (2008) Sublingual haematoma: An unusual complication of oral anticoagulation therapy About one case. Annales Franc, aises d'Anesthe'sie et de Re'animation 27: 94-96.

11. Lee M, Berger HW, Granada MG (1980) Sodium warfarin induced hemorrhage into the base of the tongue and epiglottis. Chest 77: 454455 .

\section{Your next submission with Juniper Publishers will reach you the below assets}

- Quality Editorial service

- Swift Peer Review

- Reprints availability

- E-prints Service

- Manuscript Podcast for convenient understanding

- Global attainment for your research

- Manuscript accessibility in different formats

( Pdf, E-pub, Full Text, Audio)

- Unceasing customer service

Track the below URL for one-step submission https://juniperpublishers.com/online-submission.php 